STABILIZATIOA OR COENZYTE BIKDING BY CONJUGATED STRROIDS AKD CARBOXYLIC ACIDS

8. Singer, J. Ford, L. Schirch, and $y$. Mason

Dept. of Blological Chemistry, The University of Michigan, Ann Arbor, Michigan

(Recelved 4 January 1966; in final form 7 March 1966)

VARIOUS conjugated gteroids Inhiblt the kynurenine trangaminase of rat kidney by interfering with its association with pyridoxal phosphate 1,2 . They also protect the apoenzyee fros proteolytic inactivation ${ }^{2}$, apparently as a reault of the association that causes the inhibition. In the present tudy, estradiol dieulfate (EDS), diethylstilbestrol disulfate (SDS), dehydroeplandrosterone sulfate, and several carboxylic acids were found to retard the disociation of pyridoxal phosphate (PLP) from the kynurenine holotransaninase of fresh kidney honogenates. sinflar retardation wa observed with partially-purifled serine transhydroxynethylase of rabbit -11ver and the tyrosine-a-ketoglutarate transaninase of rat liver homogenates. An irreversible lose of tyronine transaminase activity, which occurs during incubation of the homogenates at $37^{\circ}$, wa retarded by $8 D s, a-n a p h t h o a t e$, benzonte, p-aminobenzoate, and alicylate, all of which have been ahom to Induce this onzyee. This inactivation was also retarded in homogenates propared from rats injected with sDs or hydrocortisone.

\title{
Nethods and Rosults
}

Kynurenine transaminase, serine transhydroxynethylane, and tyrosine transaminase were asaajed as described previous $y^{3-5}$ unlegs otherwise indicated. 

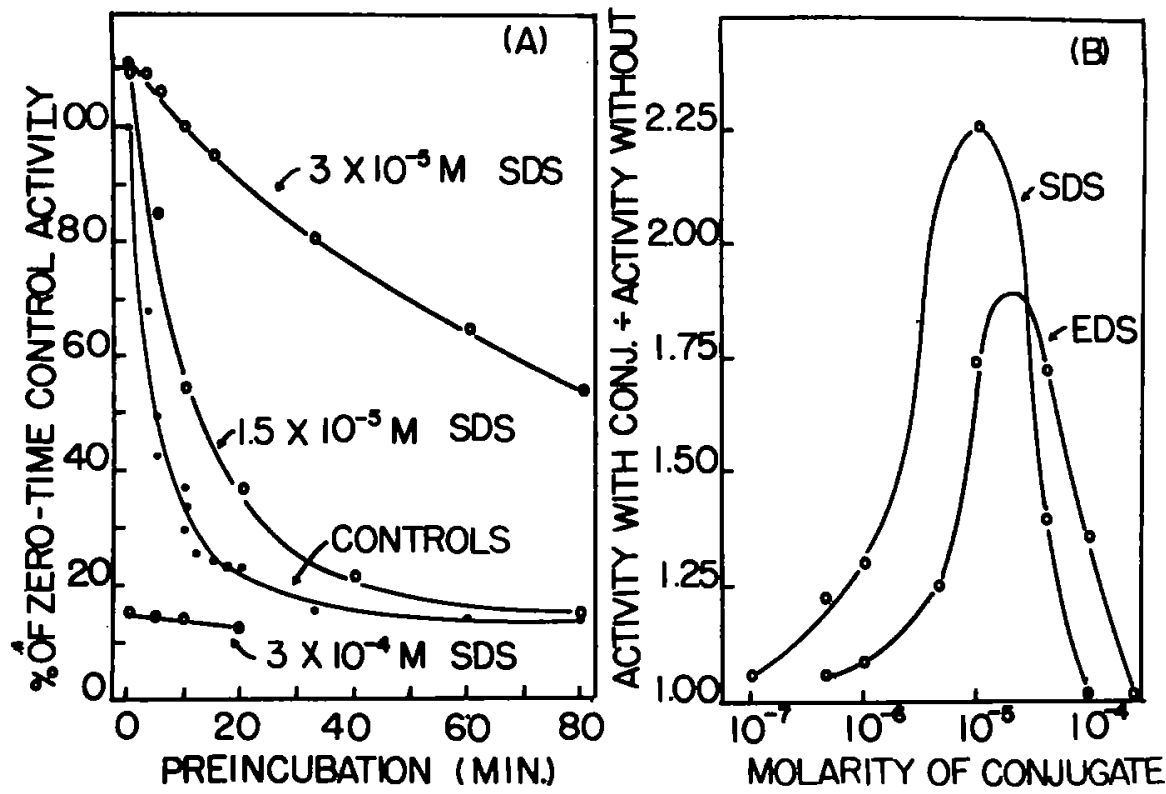

FIG. 1

(A) Retardation of the dissociation of PLP from kynurenine transaminase by various concentrations of SDS. Rat kidney was honogenized ( $1 \mathrm{gm}$ per $3 \mathrm{ml} 0.01$ Tris buffer, $\mathrm{pH} 7.4$ ) and $0.25 \mathrm{ml}$ aliquots were combined immediately with $0.25 \mathrm{ml}$ of 0.24 y sodium phosphate buffer, pH 6.3. These tubes were incubated at $37^{\circ}$ with or without added SDS. After the indicated time intervals, $0.25 \mathrm{ml}$ of 0.024 | $\alpha$-ketoglutarate was added to individual tubes to prevent further dissociation. Thirty minutes after beginning the preliminary incubations, $0.25 \mathrm{ml}$ of $0.0148 \mathrm{M}$ L-kynurenine was added to each tube gnd the activities were assayed as described previously 4 . For preliminary incubation periods extending beyond 30 minutes, L-kynurenine sulfate was added 1mmediately following the addition of a-ketoglutarate.

(B) Retardation of the dissociation of pyridoxal phosphate from kynurenine transaminase at various concentrations of SDS and EDS. Conditions were the same as described in (A) except that preliminary incubation was limited in all cases to 10 minutes in 0.12 sodium phosphate buffer, pH 6.5. The curves represent the differences in activity obtained with varying concentrations of EDS and SDS in comparison with controls. 
transaninase activity when asaryed without added PuP ${ }^{4}$. Thio activity is lost rapidly when the homogenate is pre-incubeted in phosphate buffer, pH 6.3, but is regained on the addition of PLP. We thought $1 \mathrm{t}$ probable that this apparent diseociation of pup would be accelerated by the addition of EDS or SDS, aince these compounds were assumed ${ }^{2}$ to compete for the site that binde the coenzyme. Instead, $\operatorname{SDs}\left(1.5 \times 10^{-5} \mathrm{y}\right.$ and $\left.3 \times 10^{-5} \mathrm{M}\right)$ decreased the rate of inactivation (Fig. 1A). With $3 \times 10^{-4} \times 808$, on the other hand, enzyme activity we strongly depressed even before preincubation. Retardation of dissociation was observed with concentrations of EDs and SDS in the range of $10^{-7}$ to $10^{-4} \mathrm{y}$ (Fig. 1B); higher levels caused Inhibition as predicted fros the results in F1g. IA.

Dehydroeplandrosterone sulfate and several carboxylic acids, some of which appear to be competitive inhibitors of kynurenine traneaninase 4 , also atabilized PlP binding. Dehydroepiandrosterone sulfate had little effect at levels below $10^{-4} \mathrm{u}$. Glutarate and succinate exhibited maximal stabilization at $10^{-2}$ y levels. Benzonte $\left(10^{-2} \mathrm{w}\right)$ also had a strong atabilizing action. Retardation of PLP dissociation wa also observed with serine transhydroxymethylase. The enzyoe preparation, assayed as approxinately 50\% pure, was incubated at $37^{\circ}$ in 0.1 M phosphate buffer, pH 7.3, for 20 to 30 minutes. It loses activity under these conditions and can be reactivated by added PLP. The lons of activity wa retarded at SDs levele in the range of $10^{-5}$ to $10^{-4} \mathrm{n}$.

Simllar behavior was obeerved with tyrogine transaninase. Freshly-homogenized rat liver ( 1 ga 11 ver per 7 ml water) lost activity slowly during storage at $0^{\circ}$; the activity was restored by adding Plp ( 1 mole per 5 ml incubation mixture). At $37^{\circ}$, 
oimilar unbuffered homogenaten (1 fo liver per 12 al water) lowt about $50 \%$ of their activity duxing one hour. This 1090 was largely prevented by added PLP $\left(2 \times 10^{-5}\right.$ u) but could not be revereed by adding it aftermards. The rate of ensme inactivation wae atrongly decreased by $8 \times 10^{-3}$ u bensonte, $5 \times 10^{-3}$ u amaphthoute, $7.5 \times 10^{-3}$ y p-aminobenzonte, $7.5 \times 10^{-3}$ y salicjlate, and $10^{-3}$ a a-ketoglutarate. SDs wa effective in the range of $10^{-3}$ to $2 \times 10^{-5} \mathrm{u}$.

The aromatic carboxylic ac1de and SDs ahare with the glucocorticolda the ability to induce tyrosine transaminase in adrennlectonized rate ${ }^{3}$. We therefore examined the possibility that hjdrocortieone injection alght lead to a sinilar gtabilization. Bydrocorticone (3.3 $\mathrm{mg}$ per $100 \mathrm{gm}$ body weight) was injected Intraperitoneally into 12 male Sprague-Dawley rats weighIng 160 to $185 \mathrm{gma}$. Balf of the rats were killed immediately after the injection and the rate of irreversible inactivation of the enzyee during 30 minute preincubation of the unbuffered liver homogenates at $37^{\circ}$ was determined. The rest of the animle were killed 3 hours after the injection and the activities were examined in the eame way. The rate of inactivation in the latter group was about $30 \%$ lese than that found with the controls that were tested Inediately after injection. In Bimilar experinentw, 8D8 injectione (10 mg per 100 go body weight) retarded the Inactivation by about $50 \%$.

Additional experiments were done to test whether hydrocortieone injections cause retardation of PLP dissociation from the tyrosine trapeaminase. When the homogenates were incubated 30 minutes at $0^{\circ}$, the rate of dissociation was found to be about 40\% lese for rate killed one hour after hydrocortisone injection than for the controle that were killed immediately. 


\section{Discussion}

EDS and SDS are asbumed to be analogs of PLP since they compete with it for kynurenine apotransaminase 2,6 and ohare with it the ability to protect the engye againgt proteolytic inactivation ${ }^{2}$. Their ability to retard PLP dissociation may therefore be related in gome ma to their ability to bind the active site.

The stabilization of PLP binding by a-ketoglutarate 4 was attributed to its ability, acting as an amino group acceptor, to maintain the coenzyme in its aldehydic form. In view of the present observation that non-substrate dicarboxylic and aromatic acida a 180 stabilize PLP binding, other explanations must be considered. A plausible unifying explanation for these actions of the substrate, substrate analoge, and coenzyme analoge is that they stabilize an active form of the enzyme which has a higher affinity for the coenzyme and a greater resiatance to proteolytic action.

The possibility that these and the previously observed actions 1,2 may have a significant metabolic role is suggested by analogy with studies of tryptophan pyrrolase. Tryptophan, the substrate, stabilizes the binding of hemin, the cofactor, to the apoenzyme ${ }^{7}$. This action apperently stabilizes the enzyme in vivo, leading to 1 ts accumulation in tryptophan-injected rats 7,8 . A sinilar tabilizing effect of PLP binding is suggested by the decline in the apoenzyne levels of several PLP-dependent enzymes during vitamin-B 6 deficiency ${ }^{9-11}$ and by the rapid elevation of hepatic tyrosine transaminase levels following the injection of pyridoxine $e^{12}$. It was suggested in the latter case 12 that PLP, formed from the injected pyridoxine, associates with the apotransaminase and, in some way, Increases itg synthesis or 
decreases 1 ts breakdown. Our present study denonstrates that added PIP can protect the enzyge againgt irreversible inactivation during lncubation in vitro. This ability is shered with benzoste, p-aninobenzoate, $\alpha$-naphthoate, sal1cylate, and SDS, all of which elevated tyrosine transaminase levels in iㅗo ${ }^{3}$. These observations strongly suggest that these agents cause the accumulation of hepatic tyrosine transaminase by retarding its destruction.

The observation that injected hydrocortisone caused retardation of PLP dissociation from hepatic tyrosine transaninase and that it also retarded the irreversible inactivation suggests that the glucocorticold, its metabolic derivatives, or other compounde that accunulate in the liver in response to the injection may have actions in vivo gimilar to those reported for SDs and the organic acids. The retardation of disgociation may explain the increase in the degree of saturation of hepatic tyrosine transaminase with pLp that was reported ${ }^{13}$ to occur within one hour after the injection of cortisone.

PLP is bound to vartour enzymes ${ }^{14-16}$ and to serun albumin 17 by Schiff base formation with $\epsilon$-anino groups; it is reasonable to assume that the ester phosphate group 18 also associated with cationic groups of the enzymes. The anionic character of the confugates and carboxylic acids and their abtlity to interfere with PLP binding suggests that they also bind amino groups. Recently Whitehouse and skidmore ${ }^{18}$ have pointed out that nost of the non-sterold anti-inflammatory agents are aromatic acids which interfere with the binding of PLP to serum albumin. They cited this and other evidence in support of their view that many of the actions of these agents on enzyme systems are related to their ability to bind $\epsilon$-amino groups of proteins. Our earlier observation that various aromatic acids, Including salicylate, 
resemble the conjugates and glucocorticolds in their ability to Induce tyrosine transaminase 3 and the present indications that they share with them the ability to stabilize the enzyne suggest similarities in their modes of action. Whether these actions are related in any way to the anti-inflammatory effects of various steroids and aromatic acids remains to be determined.

\section{Summary}

Estradiol disulfate and dethylstilbestrol disulfate, which interfere with the binding of pyridoxal phosphate to kynurenine apotransaminase and protect the apoenzyme from proteolytic inactivation, retarded the dissociation of pyridoxal phosphate from the holotraneaminase in freshly homogenized rat kidney. At higher concentrations, dehydroeplandrosterone sulfate and several carboxylic acids also stabilized pyridoxal phosphate binding. Similar stabilization was observed with partially purified serine tranghydroxymethylase of rabbit liver and with the tyrogine-aketoglutarate transaminase of freshly homogenized rat liver. Tyrosine transaminase activity in fresh liver homogenates (1 gm liver per 12 mls of water) lost 50\% of 1 ts activity during incubation for $1 \mathrm{hr}$ at $37^{\circ}$. This activity could not be restored by adding pyridoxal phosphate although the lose could be largely prevented by the presence of $10^{-5}$ y PLP and by $10^{-3}$ y a-ketoglutarate. Benzoate, p-aminobenzoa te, $\alpha$-naphthoate, salicylate, and diethylstilbestrol disulfate, all of which were shown previously to Induce hepatic tyrosine transaminase ln vivo, retarded the inactivation. Hydrocortisone or diethylstilbestrol disulfate infections also resulted in decreased rates of inactivation in liver homogenates prepared 3 hours after injection as compared with those prepared immediately after injection. Acknowledgenent-This work was supported in part by a USPHS grant, 
Ay-02294, and by a grant, number 299, from the University of Michigan Phoentx project.

\section{References}

1. Y. MAsON and E. GULLEKSON, J. Amer. Chen. Soc. 81, 1517 (1959).

2. M. MASON and E. GULLEKSON, J. B1ol. Chen. 235, 1312 (1960).

3. 8. SINGER and M. MABON, Blochim. Biophys. Acta 110, 370 (1965).

4. M. MSON, J. Biol, Chen. 227, 61 (1957).

5. L. SCHIRCH and $U$. MASON, J. Biol. Chem. 237, 2578 (1962).

6. V. SCARDI, 4. IACCARINO, and E. SCARANO, Biochen. J. 83, 413
(i962). 7. O. GREENGARD and P. FBIGELSON, J. B1ol. Chem. 237, 1903
(1962).

8. R. T. SHIMKE, B. W. SWEENEY, and C. M. BERLIN, J. Biol. Chem. 240, 322 (1965).

9. u. MASON and C. P. BERG, J. B1Ol. Chem. 195, 515 (1952).

10. D. B. HOPE, Blochem. J. 59, 497 (1955).

11. B. BERGERET, F. CHATAGNER, and C. FROMAGEOT, Bloch1m. BlophyB. Acta 17, 128 (1955).

12. O. GREENGARD and M. GORDON, J. B1ol. Chem. 238, 3708 (1963).

13. O. GREBIGARD, in G. Weber, Advances In Enzyme Regulation, Vol. I, p. 61, Permagon Pres8, N. Y. (1963).

14. F. H. FISCHRR, A. B. KENT, E. K. SNYDER, and E. G. KREBS, J. Amer. Chem. Soc. 80,2906 (1958).

15. R. C. HUGHES, W. T. JENKINS, and E. H. FISCHER, Proc. NatI. Acad. Sc1., U. S. 48,1615 (1962).

16. L. SCHIRCH and M. MASON, J. Biol. Chem. 238, 1032 (1963).

17. W. B. DEMPSEY and H. N. CHRISTENSEN, J. Biol. Chem. 237, 1113 (1962).

18. M. W. WHITEHOUSE and I. F. SKIDLORE, J. Phara. and Pharmacol. 17,670 (1965); Ib1d. p. 671 . 